\title{
Synthesis and Application of Nanocomposite Reinforced with Decorated Multi Walled Carbon Nanotube with Luminescence Quantum Dots
}

\author{
Jassim Hosny Al Dalaeen*, Yashfeen Khan, Anees Ahmad \\ Industrial Chemistry Laboratory, Department of Chemistry, Faculty of Sciences, Aligarh Muslim University, Aligarh, India \\ Email: *jhdalaeen89@gmail.com
}

How to cite this paper: Al Dalaeen, J.H., Khan, Y. and Ahmad, A. (2021) Synthesis and Application of Nanocomposite Reinforced with Decorated Multi Walled Carbon Nanotube with Luminescence Quantum Dots. Advances in Nanoparticles, 10, 75-93.

https://doi.org/10.4236/anp.2021.102006

Received: February 10, 2021

Accepted: May 10, 2021

Published: May 13, 2021

Copyright $\odot 2021$ by author(s) and Scientific Research Publishing Inc. This work is licensed under the Creative Commons Attribution International License (CC BY 4.0).

http://creativecommons.org/licenses/by/4.0/

(c) (i) Open Access

\begin{abstract}
Amidst the COVID-19 pandemic, environmental problems such as energy crisis, global warming, and contamination from pathogenic micro-organisms are still prevailed and strongly demanded progress in high-performance energy storing and anti-microbial materials. The nanocomposites are materials that have earned large interest owing to their promising applications for countering global issues related to sustainable energy and a flourishing environment. Here, polypyrrole coated hybrid nanocomposites of multi-walled carbon nanotube and cadmium sulfide quantum dots named MCP were synthesized using facile and low-cost in-situ oxidative polymerization method. Characterization techniques confirmed the synthesis. Electrochemical studies showed that the nanocomposite 1-MCP showed an impressively higher super capacitance behavior in comparison to $\mathrm{f}-\mathrm{MWCNT}, 7-\mathrm{MCP}$ and 5-MCP. The improved performance of the nanocomposites was attributed mainly to the good conductivity of carbon nanotubes and polypyrrole, high surface area, and stability of the carbon nanotubes and the high electrocatalytic activity of the cadmium sulfide quantum dots. Owing to the synergistic effect of MWCNT, $\mathrm{CdS}$, and PPy the synthesized ternary nanocomposite also inhibited the growth and multiplication of tested bacteria such as $S$. aureus, and $E$. coli completely within $24 \mathrm{~h}$. On the whole, the assimilated nanocomposite MCP opens promising aspects for the development of upcoming energy storage devices and as an antibacterial agent.
\end{abstract}

\section{Keywords}

Multi-Walled Carbon Nano Tube, Nanocomposite, CdS QDs, Polypyrrole, 
Super Capacitance, Anti-Bacteria

\section{Introduction}

Environmental issues, for instance, the energy crisis are leading to the scarcity of major energy resources such as coal, natural gas and petroleum at a very faster rate. In order to fulfill the growing need for feedstock, great efforts have been made by researchers to design and develop unique materials for energy conservation and energy storage [1]. The increasing demand for portable and flexible electronic devices in modern society on one hand and lack of provision of heavy cost wiring, public grids and electricity in rural areas on the other are triggering the development of lightweight, ultrathin, flexible, inexpensive, and sustainable energy storage devices that operate with high performance [2]. Among such energy storage devices, super capacitors (SCs) have mesmerized great attention due to their unique properties like high specific capacitance, high power density (Pd), low maintenance, long cycle life and environment-friendly nature [3] (Figure 1). These SCs act as an energy-power difference bridge between a traditional capacitor (having high power) and fuel cells/batteries (having high energy storage). To clarify further, the power density (Pd) and energy density (Ed) of various energy storing devices are compared with that of SC in the Ragone plot [3] [4]. This plot explains that the fuel cells are high-energy systems; whereas SCs are high-power. Batteries have intermediary power and energy capabilities. There exists some overlap in Ed and Pd of fuel cells and SCs with batteries [4]. SCs are used in electronic devices such as power supply stabilizer, flashes deliver power, grid power buffer, energy harvesting, hybrid electric vehicles and energy recovery because of their high power density, long cycle life, stability, fast charge/discharge rates, reversibility, reliability and good operational safety [5] [6]. As the Pd of SCs is high, they work on charge storage mechanism i.e. chargers are stored on the electrodes [7] [8] [9].

Recently, carbon-based nanomaterials (activated carbon, carbon nanotubes,

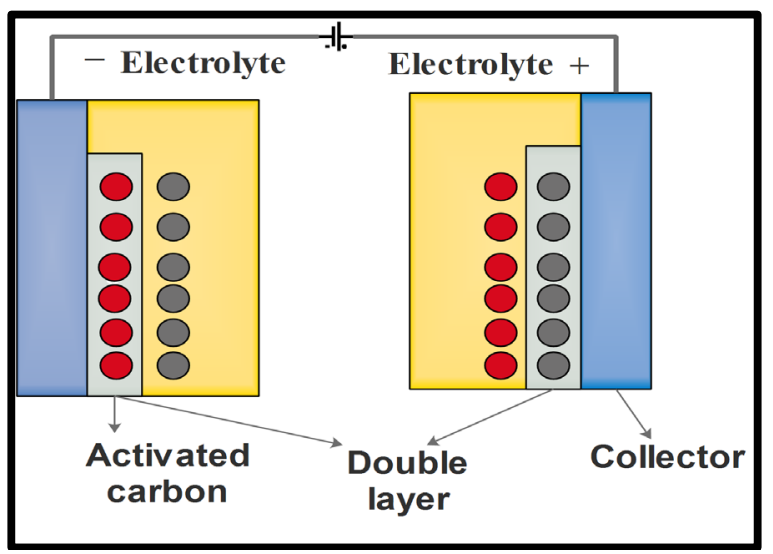

Figure 1. Design structure of a super capacitor. 
graphene, and carbon dots) are being used as a substrate for metal oxide nanoparticles and polymers for supercapacitor applications. High surface area and good electrical conductivity of carbon nanotubes leads to a faster electron transfer rate during Faradaic charge transfer reactions and thus, enhances the capacitance of CNT reinforced SCs [10] [11] [12] [13] [14].

Quantum dots (QDs) are novel nanometer range semiconductor crystals [15]. The size of QDs is smaller than the Bohr radius, ranging from $2-6 \mathrm{~nm}$ which is similar to the size of biological macromolecules such as nucleic acids and proteins [16]. Cadmium sulfide CdS-QDs falling in group II-VI of the periodic table has a band gap of $2.42 \mathrm{eV}$. They have a large surface area to volume ratio [14]. Quantum dots-based super capacitors (QDSCs) are considered promising materials, owing to the excellent properties like band gap tunability, high absorption coefficient, hot carrier extraction, multiple exciton generation, solution processibility, and low-cost facile preparation [11].

The conducting polymer (CP), polypyrrole is known to be very useful in optoelectronic devices, storage devices, photocatalysis, and electrochemical property enhancement due to its high specific capacitance, excellent thermal stability, low cost, simple manufacturing process, good environmental stability, excellent electrical conductivity [17]. These properties exist in polypyrrole due to good functionality and substitution pattern of pyrrole monomer. This conducting polymer provides the advantages of chemical diversity: corrosion resistance, flexibility, and low density. Binary composite such as PPy/CdS and CNT/PPy has been reported in the literature [5] [17]-[22]. On blending PPy with CdS-QDs, the electrical conductivity enhances by the electron-hole recombination of hole-enriched PPy and electron enriched CdS. Also, CdS quantum dots, when combined with $\mathrm{PPy}$, are protected from photo corrosion [23]. Poor life cycle stability is a major drawback of PPy based super capacitors which is mastered by the addition of CNTs due to their high surface area, high electric conductivity, chemical and mechanical stability [17]. To the best of our knowledge, the interfacial structure between nanotube and polymer including the morphology and thickness of polymer is critical to tailor their structures and properties in many potential applications [24]. Thus, designing the hybrid nanocomposite structure of the electro capacitive materials is one of the effective ways to achieve a large surface area and high conductivity. This in turn provides more faradaic reaction sites and accelerating the charge transfer, respectively, and therefore enhances the electro capacitive performance of super capacitors [25].

The present study attempts to fill the knowledge gap by investigating the synthesis, electrochemical ability, and antimicrobial efficacy of MCP nanocomposite and helping up us to some extent in eradicating environmental issues. Electrochemical studies revealed that the nanocomposite 1-MCP showed an impressively high super capacitance behavior in comparison to f-MWCNT, 7-MCP and 5-MCP with enhanced anodic and cathodic current levels of ( $I p a=4.740 \mathrm{~A}, I p c$ $=-3.150 \mathrm{~A})$. Consequently, it was reported that a high content of $\mathrm{f}-\mathrm{MWCNT}$ is not favorable for the super capacitance behavior [5]. The improved performance 
of the nanocomposites was attributed mainly to the good conductivity of carbon nanotubes and polypyrrole, high surface area, and stability of the carbon nanotubes and the high electrocatalytic activity of the cadmium sulfide quantum dots. Furthermore, the assimilated nanocomposites also showed momentous anti-bacterial ability with ZOI reported to be $11 \mathrm{~nm}, 12 \mathrm{~nm}$, and $12 \mathrm{~nm}$ for 1-MCP, 5-MCP, and 7-MCP respectively, when screened against E. coli and $S$. aureus. On the whole, the assimilated CNT reinforced nanocomposite opens up promising aspects in both the areas viz. designing of energy storage devices as well as bactericidal efficacies.

\section{Materials and Methods}

\subsection{Chemical Reagents and Materials}

Pyrrole (PPy) and multi-walled carbon nanotubes (MWCNT) were purchased from Sigma and Aldrich. Cadmium sulfate from Fisher Scientific, thioacetamide (TAA) from Finar chemicals and ferric chloride was taken from $\mathrm{CDH}$.

\subsection{Acid functionalization of MWCNT}

$(1 \mathrm{~g})$ was added to $200 \mathrm{ml}$ of $\left(\mathrm{HNO}_{3}: \mathrm{H}_{2} \mathrm{SO}_{4}\right)$ in $1: 3$ ratio yielding f-MWCNT. This acid functionalization changes the character at the ends of the MWCNTs from hydrophobic to hydrophilic by the addition of - $\mathrm{COOH}$ group [26].

\subsection{Preparation of MWCNT/CdS Binary Nanocomposite}

$200 \mathrm{mg}$ of (f-MWCNT) dispersed in $250 \mathrm{ml}$ DDW by ultra-sonication for 30 min, (named as, Sol-I) and $184 \mathrm{mg}$ of thioacetamide (TAA) is dissolved separately in $10 \mathrm{ml} \mathrm{DDW}$ (named as, Sol-II). Also, $50 \mathrm{mg}$ of cadmium sulfate $\left(\mathrm{CdSO}_{4}\right)$ is dispersed in $10 \mathrm{ml} \mathrm{DDW}$ for $3 \mathrm{~h}$ (named as, Sol-III) is prepared. Then, dispersion of (Sol-III) to (Sol-I) using sonicator is done for $2 \mathrm{~h}$. Lastly, $2 \mathrm{~h}$ ultra-sonication of (Sol II) and (Sol I) together followed by centrifugation at $3200 \mathrm{rpm}$ for $10 \mathrm{~min}$ yields MWCNT/CdS (MC) after washed with double distilled ethanol and DDW and overnight drying at $65^{\circ} \mathrm{C}$ in oven Scheme 1.

\subsection{Chemical Polymerization of Pyrrole into MC: Conversion of Binary to Ternary MCP Nanocomposite}

Variable amounts of the above synthesized MC viz $0.01 \mathrm{~g}, 0.05 \mathrm{~g}$ and $0.07 \mathrm{~g}$ are taken. $0.1 \mathrm{M} \mathrm{FeCl}_{3}$ solution dissolved in $100 \mathrm{ml}$ of DDW is added to each variable amount. Further, $0.987 \mathrm{~g}$ of pyrrole is added in the above solution, sonicated for $4 \mathrm{~h}$. Ternary solution is centrifuged at $3800 \mathrm{rpm}$, washed with DDW and double distilled ethanol, kept overnight in oven at $65^{\circ} \mathrm{C}-70^{\circ} \mathrm{C}$. Finally, the dried product obtained is MCP. The proposed mechanism is shown in Scheme 2.

\subsection{Characterization}

High resolution transmission electron microscopy (HRTEM), Scanning electron microscopy (SEM), energy dispersive X-ray (EDX) and mapping analysis were 


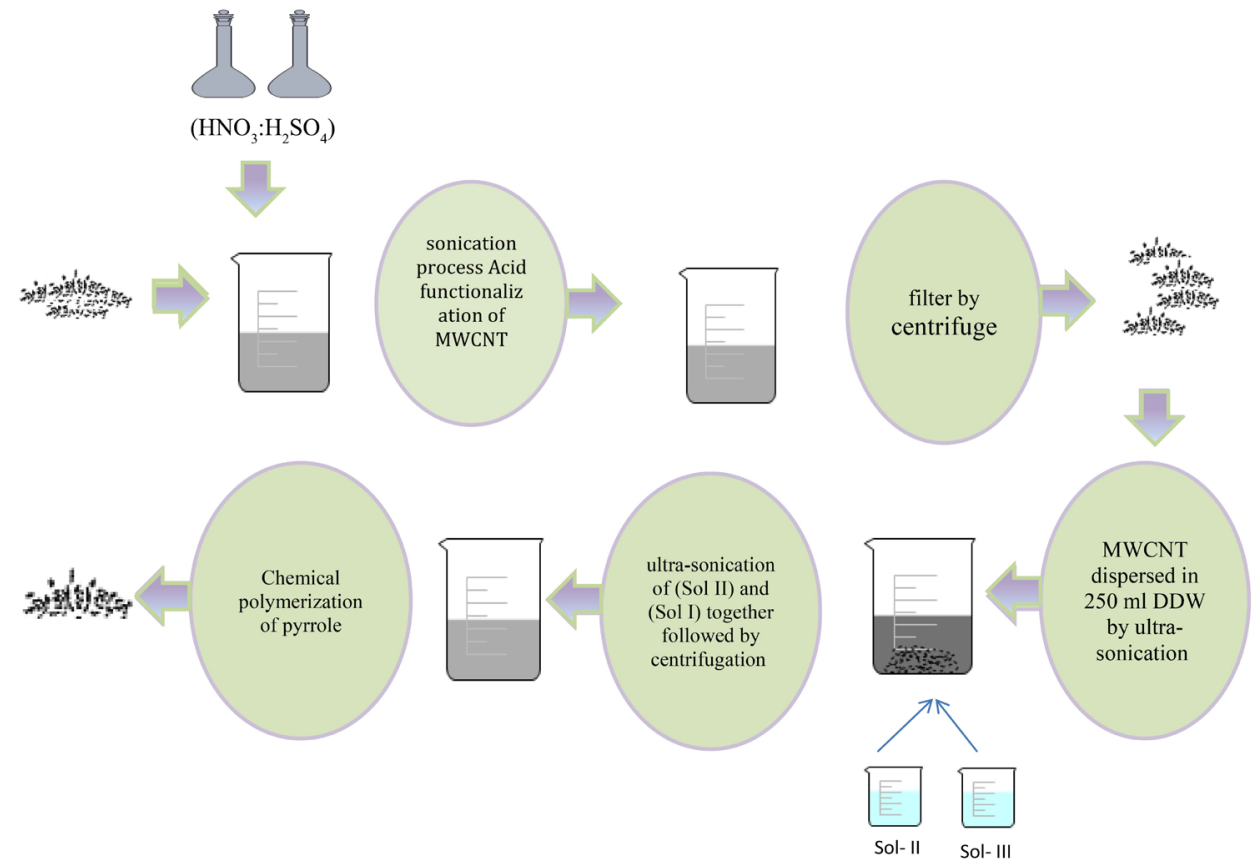

Scheme 1. Schematic of the synthesis of MWCNT/CdS/PPy.



Scheme 2. Schematic illustration of the synthesis of MWCNT/CdS/PPy. 
performed on JEOL H-7500 microscope and LEO 435-VF, respectively. Fourier transform infrared (FTIR) spectra were obtained from Perkin-Elmer spectrophotometer (Model Spectrum-BX, USA) in the wavelength range of $4000-400$ $\mathrm{cm}^{-1}$.

\subsection{Electrochemical Measurements}

Electrochemical studies were done on a cell having 3 electrodes system with platinum wire as the counter electrode (or CE) color black, platinum solid as working electrode color red, and $\mathrm{Ag} / \mathrm{AgCl}(3 \mathrm{M}, \mathrm{KCl})$ as the reference electrode (RE) color green on Electrochemical workstation (Model PGT-204, Neatherland). The potential was swept from -0.1 to $+0.6 \mathrm{~V}$ vs. $\mathrm{Ag} / \mathrm{AgCl}(3 \mathrm{M}, \mathrm{KCl})$ with $5 \mathrm{sec}$ of rest time before measurements. The scan rates were $10 \mathrm{mVs}^{-1}, 25 \mathrm{mVs}^{-1}, 50$ $\mathrm{mVs}^{-1}$, and $100 \mathrm{mVs}^{-1}$. A cyclic voltammetry and electrochemical impedance spectroscopy (EIS) studies were carried out. The CV analysis was performed in 1 $\mathrm{M} \mathrm{KCl}$ solution and EIS estimation done using frequency response analyzer coupled with potentiostat with frequency ranging from 0.1 to $10^{5} \mathrm{~Hz}$ with alternate current amplitude of $10 \mathrm{mV}$.

\subsection{Test Microorganisms}

Some clinical isolates of bacterial strains were selected on the basis of their clinical importance in causing diseases in humans. These were obtained from Jawaharlal Nehru Medical College \& Hospital Microbial. The strains so selected for the study are Staphylococcus aureus (gram positive) and Escherichia coli (ATCC 25922), as gram negative bacterial strains. These strains were screened for evaluation of antibacterial activities of the synthesized chemical compounds.

Medium. The solid media namely Nutrient Agar No.2 (NA) (M 1269S-500G, Himedia Labs Pvt. 4 Ltd., Bombay, India) was used for preparing nutrient plates, while Nutrient Broth (NB) (M002-500G, Himedia Labs Pvt. Ltd., Bombay, India), used for the liquid culture media. The antibacterial activities of the synthesized compounds were evaluated by agar well diffusion method. All the microbial cultures were adjusted to $0.5 \mathrm{McF}$ arland standards, which is visually comparable to a microbial suspension of $1.5 \times 10^{8} \mathrm{cfu} / \mathrm{ml} .20 \mathrm{ml}$ of agar media was poured into each Petri plate and plates were swabbed with a colony from the inoculums of the test microorganisms and kept for 15 min for adsorption. Using sterile cork borer of $6 \mathrm{~mm}$ diameter, wells were bored into the seeded agar plates and these were loaded with a $50 \mu \mathrm{l}$ volume with concentration of $10 \mathrm{mg} / \mathrm{ml}$ of each compound reconstituted in the dimethylsulphoxide (DMSO). All the plates were incubated at $37^{\circ} \mathrm{C}$ for $24 \mathrm{~h}$.

\section{Results and Discussion}

\subsection{FTIR Spectroscopic Analysis}

Figure 2 shows the FTIR spectra of (a) $0.07 \mathrm{wt} \% \mathrm{MWCNT/CdS/PPy,} \mathrm{(b)} 0.05$ wt\% MWCNT/CdS/PPy, (c) $0.01 \mathrm{wt} \%$ MWCNT/CdS/PPy nanocomposites. The 




Figure 2. FTIR spectra of (a) 7-MCP; (b) 5-MCP; (c) 1-MCP nanocomposites.

broad peak at $3400 \mathrm{~cm}^{-1}$, indicates the $(\mathrm{O}-\mathrm{H})$ extension of the hydroxyl group [27]. The peak at $1740 \mathrm{~cm}^{-1}$ indicates that $-\mathrm{COOH}$ group (attached on the surface of MWCNT due to acid functionalization) changes to carboxylate group $\left(-\mathrm{COO}^{-}\right)$on the formation of MWCNT/CdS indicating the bonding of $\mathrm{Cd}^{2+}$ with $-\mathrm{COO}^{-}$on the surface of MWCNT [28]. Peaks appearing at $1570 \mathrm{~cm}^{-1}$ and 1497 - $1430 \mathrm{~cm}^{-1}$ in the synthesized nanocomposites represent the characterization peaks of polypyrrole indicating successful polymerization of pyrrole. These peaks are attributed to anti-symmetric, and symmetric and anti-symmetric C-C stretching vibration of pyrrole ring, respectively [29]. Meanwhile, the stretching vibration peak ascribable to $\mathrm{C}-\mathrm{C}$ can also be observed at $1548 \mathrm{~cm}^{-1}$, this peak strengthens with the increase in MWCNT wt\%. Therefore, it can be concluded that there are chemical bonding functions among the MWCNTs and CdS nanoparticles in the nanocomposite [30] [31]. The bands at 1276, 1148 and $1053 \mathrm{~cm}^{-1}$ are associated with the $\mathrm{C}-\mathrm{H}$ bending modes [29]. However, with the increase in wt $\%$ of MWCNT, minute shifting of FTIR peaks is observed. These shifts in the peak positions may arise due to the strong synergetic interaction between the MWCNTs, CdS, and PPy.

\subsection{Morphological Interpretation (SEM, TEM, EDAX, Mapping and SAED)}

(Figures 3(a)-(c) and Figures 3(e)-(g)) illustrate the TEM and SEM micrographs at different resolutions for synthesized MWCNT/CdS/PPy nanocomposite, respectively at different magnifications. (Figures 3(a)-(c)) show the complete internal morphology of the material where elongated MWCNTs tubes are surrounded by spherical shaped CdS QDs enwrapped in the PPy matrix and only a few MWCNTs are on the loose outside, same as in $\mathrm{MWCNTs} / \mathrm{TiO}_{2}[30]$ and 


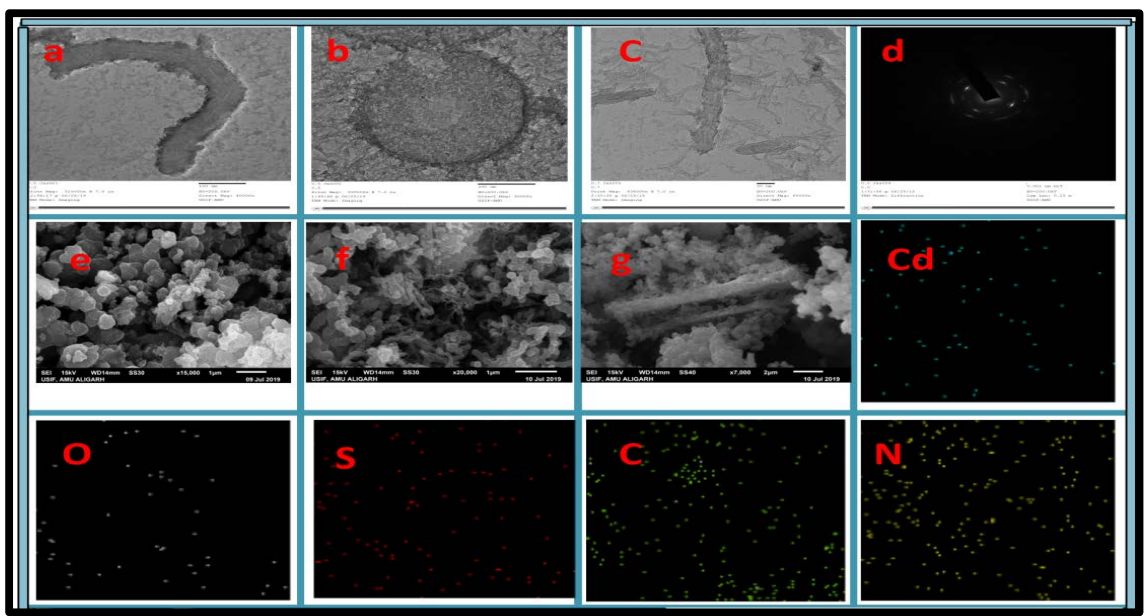

Figure 3. Micrographs of transmission electron microscopy (a, b, c); SAED: selected area electron diffraction pattern (d); scanning electron microscopy (e, f, g) and elemental mapping (C, N, O, S, and Cd) in MWCNT/CdS/PPy nanocomposite.

MWCNT/PPy hybrid composite [29] [32] [33]. The later suggests that the interaction between PPy and MWCNTs overpowers the vander Waals interaction between MWCNTs and form bonds with PPy [29]. CdS QDs are tightly bound on the surface of MWCNT declaring the chemical bonds between the CdS and MWCNTs [34]. The chemical bonding between the MWCNTs and CdS QDs would be advantageous in the charge transfer which is discussed further in the paper [30] [31] [35]. The SAED pattern in (Figure 3(d)) shows well-defined ring like distribution of the particles, this along with the SEM images gave evidences for the crystalline nature of the nanocomposite [36]. Elemental mapping, an advanced analysis technique represents the qualitative distribution of elements in the samples. It records all possible elemental information about the specimen portion under study. (Figure 3) clearly depicts the well-defined distribution of $\mathrm{C}, \mathrm{O}, \mathrm{N}, \mathrm{Cd}$ and $\mathrm{S}$ in the designed nanocomposite. (Figure 4) indicates the energy dispersive X-Ray analysis (EDAX) results and the corresponding weight percentage of all the elements present in the nanocomposite material. The EDAX gave the further confirmation for the presence of $\mathrm{Cd}, \mathrm{S}$ and $\mathrm{N}$ (of polypyrrole) in the ternary composite and also the other elements, $\mathrm{C}, \mathrm{O}, \mathrm{Fe}$, and $\mathrm{Cl}$.

\subsection{Electrochemical Investigation}

(Figure 5) represents the cyclic voltammetry (CV) curves of f-MWCNT, 0.07 wt\% MWCNT/CdS/PPy, 0.05 wt\% MWCNT/CdS/PPy, and 0.01 wt\% MWCNT/ $\mathrm{CdS} / \mathrm{PPy}$ nanocomposites measured at scan rates $10 \mathrm{mVs}^{-1}, 25 \mathrm{mVs}^{-1}, 50 \mathrm{mVs}^{-1}$ and $100 \mathrm{mVs}^{-1}$ within the potential window ranging from -0.1 to $+0.6 \mathrm{~V}$. As observed in (Figure 6), $0.01 \mathrm{wt} \% \mathrm{MWCNT/CdS/PPy} \mathrm{nanocomposite} \mathrm{encloses}$ largest area and hence, excellent capacitive behavior in comparison to f-MWCNT, $0.07 \mathrm{wt} \% \mathrm{MWCNT/CdS/PPy}$ and $0.05 \mathrm{wt} \%$ MWCNT/CdS/PPy with enhanced current levels (Ipa $=$ of $4.740 \mu \mathrm{A}, \mathrm{Ipc}=-3.150 \mu \mathrm{A})$ [37]. The improved performance of the nanocomposites can be explained by the synergetic effect of highly 


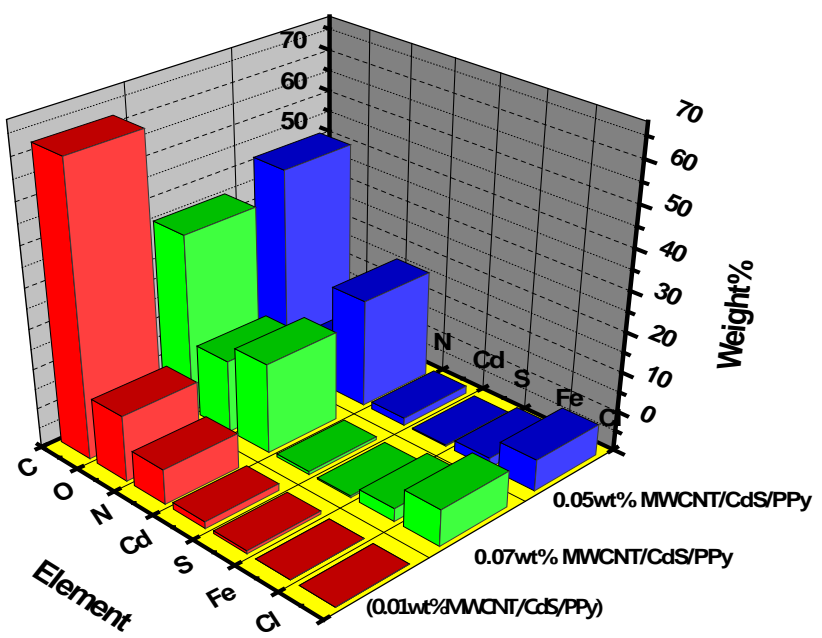

Figure 4. Showing elemental composition by energy dispersive X-Ray analysis (EDAX) technique.

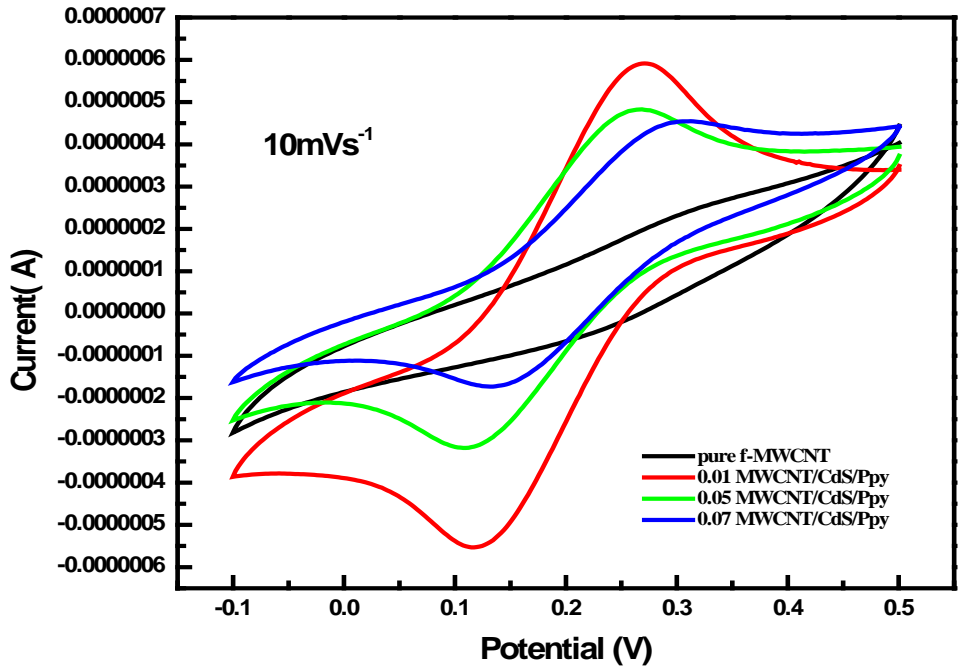

Figure 5. Cyclic voltammetric graphs for pure f-MWCNT, $0.01 \% \mathrm{MWCNT} / \mathrm{CdS} / \mathrm{PPy}$, $0.05 \% \mathrm{MWCNT} / \mathrm{CdS} / \mathrm{PPy}$ and $0.07 \% \mathrm{MWCNT} / \mathrm{CdS} / \mathrm{PPy}$ measured at scan rate $10 \mathrm{mVs}^{-1}$.

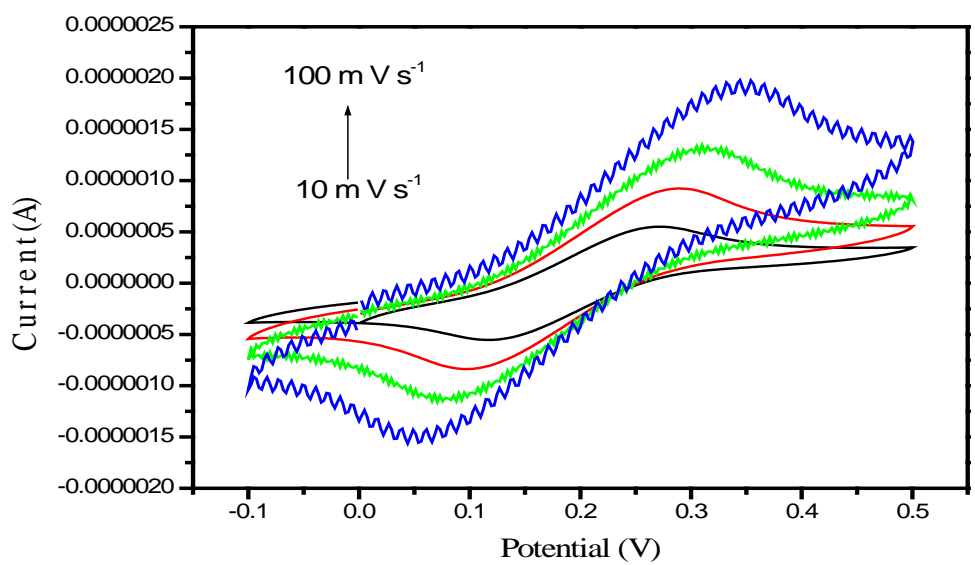

Figure 6. Effect of scan rate on the super capacitance behavior of the designed nanocomposite $0.01 \mathrm{wt} \% \mathrm{MWCNT} / \mathrm{CdS} / \mathrm{PPy}$. 
pseudo capacitive polypyrrole, CdS [14] [38] [39] and highly conductive f-MWCNT [28] [33] [37] resulting in enhanced electronic conductivity and specific capacitance thus, improving electrochemical properties, such as energy storage capacity for the hybrid nanocomposite compared to pure f-MWCNT.

\subsection{CV of the Designed Nanocomposite at Different Scan Rate: Effect of Scan Rate on Super Capacitance Behavior of MWCNT/CdS/PPy}

It depends on the potential sweep rate, as described in reported literature [40]. It is studied to assess whether the processes in the assimilated nanocomposite is diffusion controlled or adsorption controlled. Figure 6 shows CV area is increasing with the increase in scan rates, this implies the increase in capacitance. Also, with the increase in scan rate, Epa is shifting towards more positive potential and thus leading to the increase in peak currents, (IPa) as shown in Table 1. The peak current for anodic oxidation is proportional to the square root of the scan rates (Figure $7(\mathrm{a})$ ).

Figure 7(a), Figure 7(b) show that the current Vs scan rate graphs follow linear regression equation between the peak currents and the scan rates. The linear regression equation gives information on the diffusion controlled reaction process [41]. The obtained linear Equation.

Table 1. Effect of scan rate on anodic and cathodic peak currents and potentials.

\begin{tabular}{ccccc}
\hline Scan rate $\left(\mathrm{mVs}^{-1}\right)$ & $I p a(A)$ & $I p c(A)$ & Epa $(V)$ & Epc $(V)$ \\
\hline 10 & 4.740 & -3.150 & 0.257 & 0.115 \\
25 & 6.930 & -5.057 & 0.282 & 0.093 \\
50 & 9.510 & -6.755 & 0.306 & 0.083 \\
100 & 13.176 & -9.080 & 0.349 & 0.060
\end{tabular}

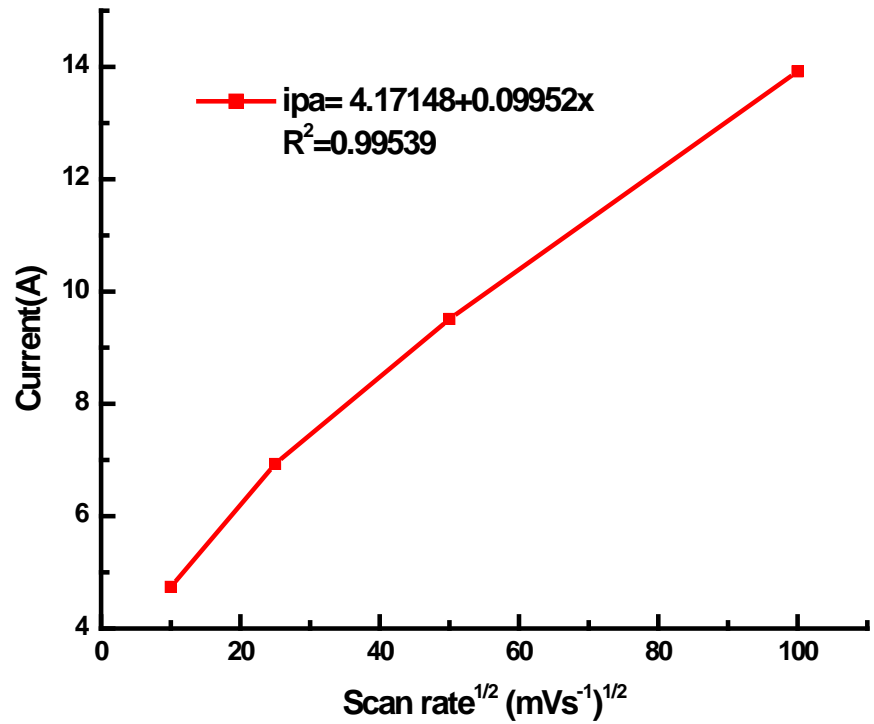

(a) 


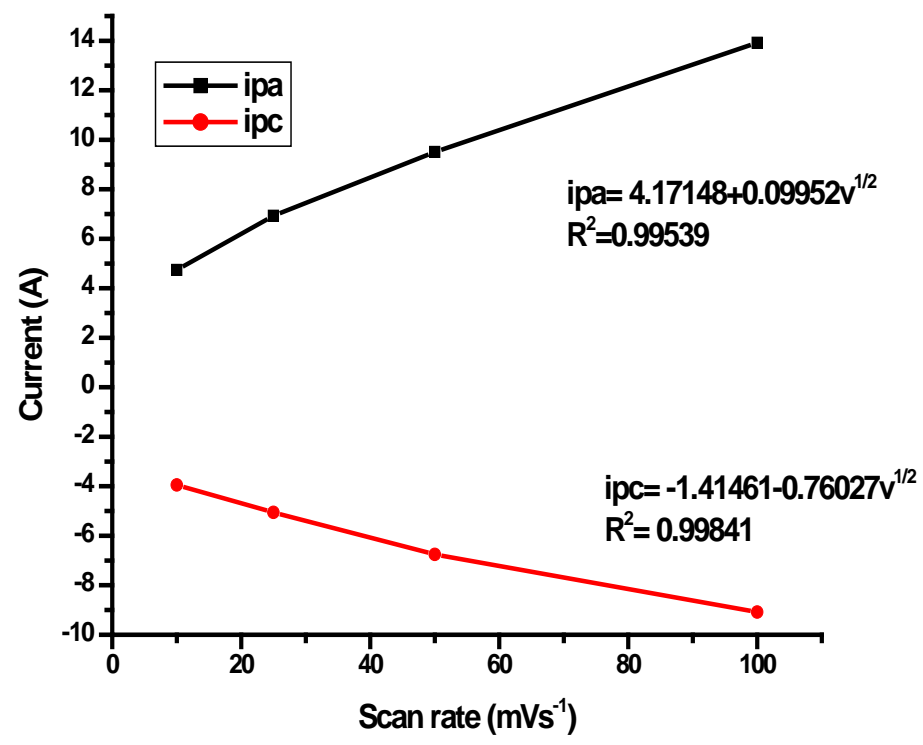

(b)

Figure 7. Plot of anodic current at $0.2574 \mathrm{~V}$ vs. square root of the scan rate (a). Plot of anodic current at $0.2574 \mathrm{~V}$ (Ipa) and cathodic current at $0.1158 \mathrm{~V}$ (Ipc) vs. scan rate (b).

$$
\begin{gathered}
\operatorname{Ipa}(A)=4.17148+0.9952 \mathrm{v}\left(\mathrm{mVs}^{-1}\right) \\
R^{2}=0.99639
\end{gathered}
$$

And

$$
\begin{gathered}
\operatorname{Ipc}(A)=-1.41810-0.78027 \mathrm{v}\left(\mathrm{mVs}^{-1}\right) \\
R^{2}=0.99841
\end{gathered}
$$

According to the Equation,

$$
I p=n F Q v / 4 R T
$$

where Ipa and Ipc are anodic and cathodic current peaks, respectively, $n$ is the number of electrons, $F$ is the Faraday's constant, $Q$ is the electric quantity, $v$ is the potential scan rate, and $T$ is the thermodynamic temperature. The peaks of anodic and cathodic current are linearly proportional to the scan rate, based on the linear equation. This indicates that the electrocatalytic behavior of nanocomposite involved surface electron transfer [42].

\subsection{Electrochemical Impedance Spectroscopy (EIS): Nyquist Plot and Bode Plot}

To further confirm the capacitive behavior in synthesized nanocomposites, the electrochemical properties were fully investigated by electrochemical impedance spectroscopy (EIS). The corresponding circuit (Figure 8(a)) is solved (S 1) The EIS can be expressed in terms of Nyquist plot, Figure $8(\mathrm{a})$, Figure $8(\mathrm{~b})$, where circuit calculation is shown in Figure 8 (a). In our system, the Nyquist plots have two semicircles and a linear portion (slightly slanting at $45^{\circ}$ ). The first semicircle in the high frequency (larger than $10^{4} \mathrm{~Hz}$ ), represents solution resistance (Rs) arising from difficulty in electrochemical reactions at the electrode/ 

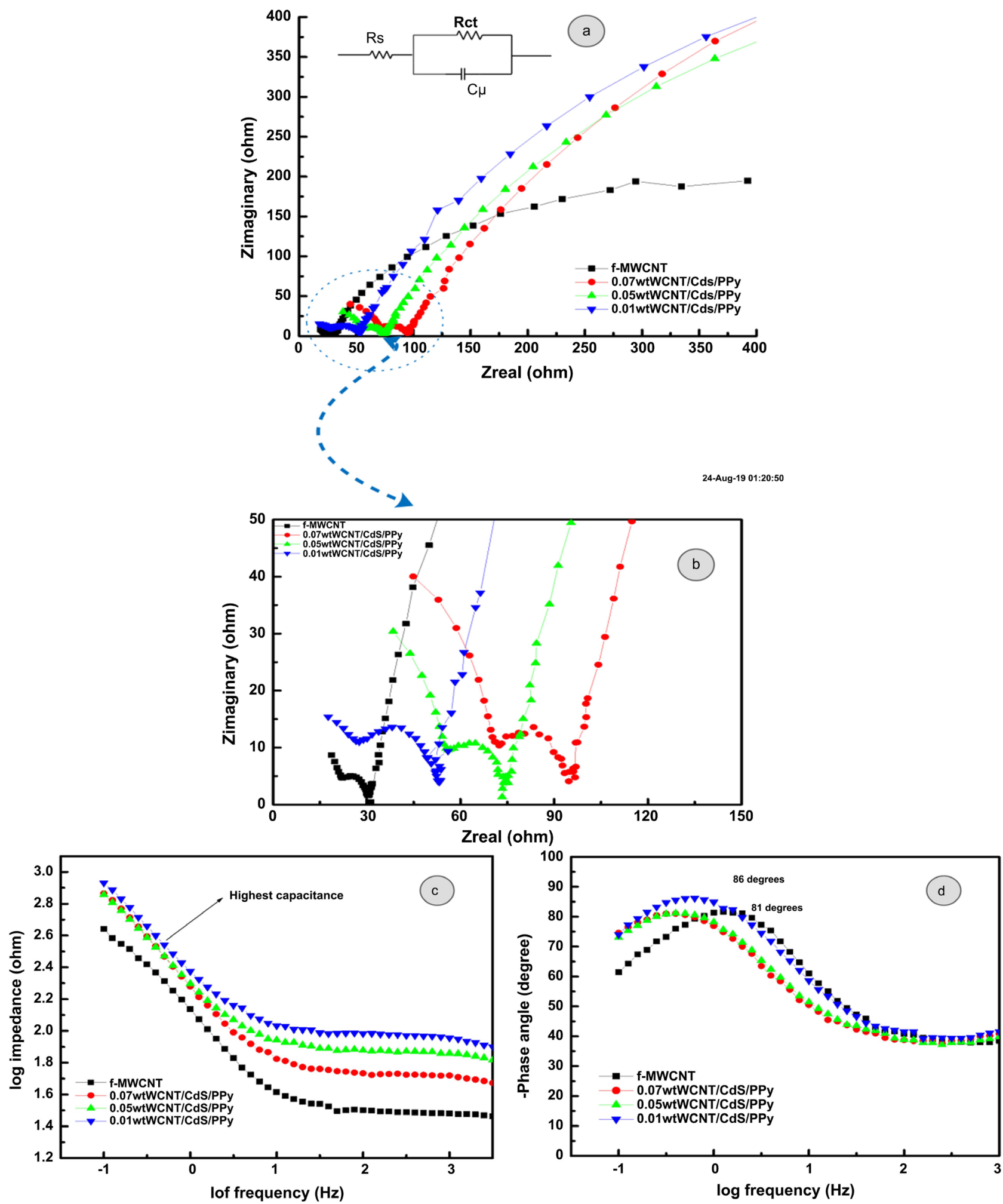

Figure 8. Nyquist plots $(\mathrm{a}, \mathrm{b})$ and Bode plots $(\mathrm{c}, \mathrm{d})$ to study the charge transfer mechanism and super capacitance.

electrolyte interface. This Rs is extracted by the intercept of the semi-circle on the $\mathrm{x}$-axis of the plot (Zreal, representing ohmic property). Rs data determines the rate at which the SC can be charged or discharged and it is a vital factor to 
predict power density of SC, since power density is inversely proportional to (Rs) [43], whereas the second semicircle appearing in the medial frequency region $\left(10^{4}\right.$ to $1 \mathrm{~Hz}$ ) is proceeded from the charge transfer resistance (Rct) and the corresponding chemical capacitance $(\mathrm{C} \mu)$ at the electrode/electrolyte interface [11]. The diameter of EIS semi-circle is directly proportional to the resistance in the electrons mobility at the electrode/electrolytic interface. Larger the diameter, higher will be the charge transfer resistance and lower will be the electron mobility (flow of current) in the cell. Therefore, EIS evaluations justify the CV curves [38].

The linear portion (nearly parallel to the $Z$ imaginary y axis) in the low-frequency region (less than $1 \mathrm{~Hz}$ ), corresponds to the Warburg diffusion impedance $\left(Z_{W}\right)$ within the electrolyte suggesting the capacitor property [5] [11]. Long lines of $Z_{w}$ indicate diminished access of electrolytic ions [43] [44]. At high frequency, material with super capacitance behaves as a pristine resistor while at low frequency as a pristine capacitor. The Nyquist plots fitted by the equivalent circuit were demonstrated in Figure 8(b). The relationship between the imaginary impedance $|Z|$ and the frequency $f$ can be acquired from EIS measurements. The capacitance $(C)$ can be calculated using Equation (4)

$$
C=\frac{1}{2 \pi f Z}
$$

using a linear portion of a $\log |Z|$ vs. $\log f$ curve, which is called the Bode plot. Figure $8(\mathrm{c})$, the Bode plot of frequency vs. impedance shows that the capacitance decreases with increasing frequency [9]. The plots indicate small resistance at high frequency and show slant lines with negative slopes $(-1)$ at low frequency implying near ideal capacitive behavior of nanocomposites. Figure 8(c), Figure 8(d) shows another derivative of Bode plot which compliments the results of Nyquist Plot. The maximum phase angle of $86^{\circ} \mathrm{C}$ shown by $0.01 \mathrm{wt} \%$ MWCNT/ $\mathrm{CdS} / \mathrm{PPy}$ indicates highest capacitive behavior with enormous storage capacity than other nanocomposites and the f-MWCNT [39] [45].

\subsection{In-Vitro Bactericidal Efficacy}

Figure 9 shows, bactericidal efficacy of all the prepared nanocomposites checked by measuring the ZOI against the test microorganisms with Antibiotic Zone Scale (PW297, Himedia Labs Pvt. Ltd., Mumbai, India), which was held over the back of the inverted plate. The plate was held a few inches above a black, nonreflecting background and illuminated with reflected light. DMSO was used as a -ve control while Gentamicin (standard antibiotic for gram negative) was used as +ve control. MIC calculations were done by standard protocol of NCCLS document M7-A3 by 96-well plate micro dilution method, (Table 2). The antibacterial efficacy of sample A, B and C was checked against $E$. coli (gram-negative) (MTCC-405) and $S$. aureus (gram-positive) (MTCC-3160) by Agar diffusion method. Briefly, discs $(6 \mathrm{~mm})$ were stationed on the agar plates and various concentrations of sample A, B and C suspended in 25\% DMSO were pipetted onto filter discs (Table 3) [46] [47]. 


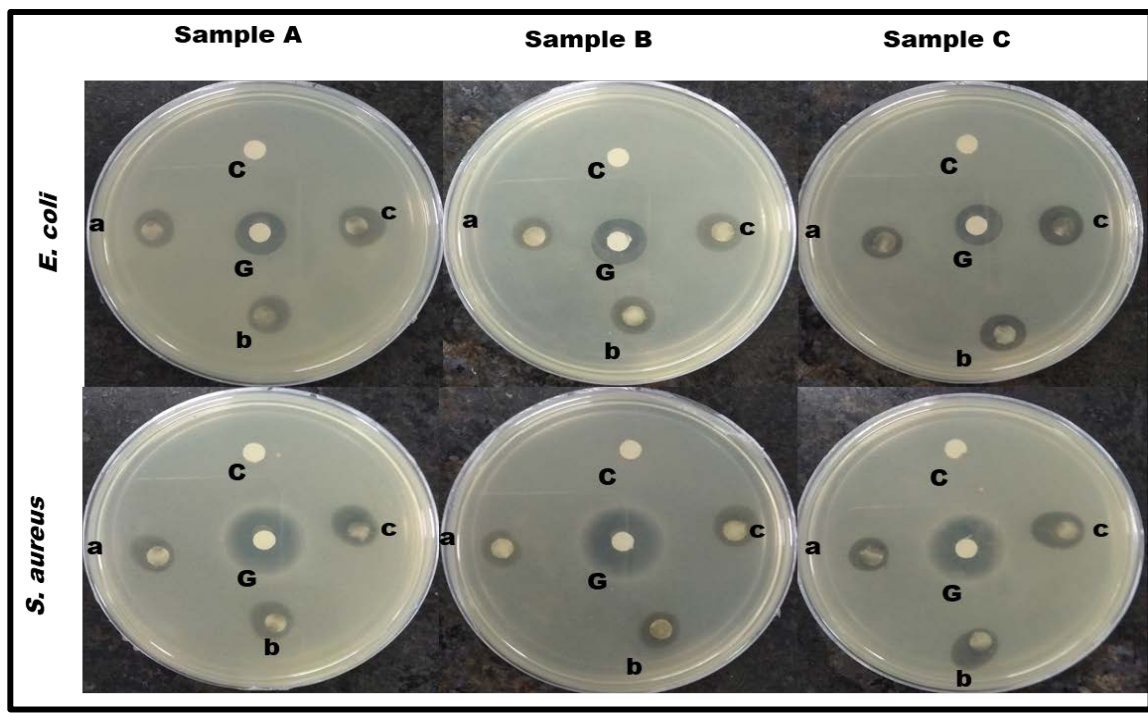

Figure 9. Disk diffusion assay of E. coli and $S$. aureaus showing zone of inhibition in the presence of Sample A, B and C at a concentration of (a) $100 \mu \mathrm{g}$, (b) $125 \mu \mathrm{g}$ and (c) $150 \mu \mathrm{g}$. The controls represent (G) Gentamycin, and (C) 25\% DMSO.

Table 2. Minium inhibitory concentration $(\mu \mathrm{g} / \mathrm{ml})$ of sample A $(0.07 \mathrm{wt} \%$ MWCNTl $C d S / P P y), \mathrm{B}(0.05 \mathrm{wt} \% M W C N T / C d S / P P y)$, and C (0.01 wt\% MWCNT/CdS/PPy), against E. coli and $S$. aureus.

\begin{tabular}{ccc}
\hline & \multicolumn{2}{c}{ MIC $_{90}(\mu \mathrm{g} / \mathrm{ml})$} \\
\cline { 2 - 3 } Samples & E. coli & S. aureus \\
\hline Sample A & \pm 300 & \pm 150 \\
Sample B & \pm 150 & \pm 150 \\
Sample C & \pm 75 & \pm 150 \\
Gentamycin & 12 & $0.5-2$
\end{tabular}

Table 3. Disk diffusion assay of Sample A, B and C against different E. coli and S. aureus.

\begin{tabular}{ccccccc}
\hline & \multicolumn{5}{c}{ Zone of Inhibition (mm) } \\
\cline { 2 - 7 } \begin{tabular}{c} 
Concentration \\
\cline { 2 - 7 }$/ \mathrm{ml}$
\end{tabular} & \multicolumn{5}{c}{ E. coli } & \multicolumn{5}{c}{ S. aureus } \\
\cline { 2 - 7 } & Sample A & Sample B & Sample C & Sample A & Sample B & Sample C \\
\hline Sample A (100) & 11 & 11 & 12 & 11 & 12 & 12 \\
Sample A (125) & 13 & 12 & 13 & 12 & 13 & 14 \\
Sample A (150) & 15 & 14 & 14 & 14 & 14 & 15 \\
$25 \%$ DMSO & - & - & - & - & - & - \\
Gentamicin (5) & 14 & 14 & 14 & 20 & 20 & 20 \\
\hline
\end{tabular}

\section{Conclusion}

In summary, we have assimilated a high-performance, flexible, huge storage capacitive super capacitor by incorporating cadmium sulfide and polypyrrole into multi-walled carbon nanotubes using a sol-gel chemical approach. Various cha- 
racterization techniques confirmed the successful assimilation of a treble nanocomposite. Electrochemical studies showed that the nanocomposite $0.01 \mathrm{wt} \%$ $M W C N T / C d S / P P y$ showed an impressively higher super capacitance behavior in comparison to f-MWCNT, 0.07 wt\% MWCNT/CdS/PPy and 0.05 wt\% MWCNT/CdS/PPy with enhanced current levels of (ipa $=4.740 \mathrm{~A}$, ipc $=-3.150 \mathrm{~A}$ ). The improved ability of the nanocomposites was attributed mainly to the good conductivity of carbon nanotubes and polypyrrole, high surface area, and stability of the carbon nanotubes and the rich electrocatalytic activity of the cadmium sulfide quantum dots. Although, consecutively high content of f-MWCNT is not favorable for the super capacitance behavior, on the whole, the assimilated nanocomposite MWCNT/CdS/PPy opens promising aspects for the development of upcoming energy conversion and energy storage devices. Besides, the designed nanocomposite also showed the considerate anti-bacterial effect with ZOI: $11 \mathrm{~nm}, 12 \mathrm{~nm}$ and $12 \mathrm{~nm}$ for $0.01 \mathrm{wt} \% \mathrm{MWCNT} / \mathrm{CdS} / \mathrm{PPy}, 0.05 \mathrm{wt} \% \mathrm{M}$ WCNT/CdS/PPy and 0.07 wt\% MWCNT/CdS/PPy respectively when screened against $E$. coli and $S$. aureus bacteria. Altogether, the study extends new strategies and applications towards the eradication of energy crisis, development of energy storage devices with improved anodic and cathodic currents.

\section{Acknowledgements}

The authors are gratified to thank the Department of Chemistry, Faculty of Sciences, Department of Petrochemical Engineering, Faculty of Engineering and Technology, Department of Agricultural Microbiology, Faculty of Agricultural Science, Aligarh Muslim University, for providing the research facilities. Authors are indebted to the University Grant Commission (UGC), Government of India for financial aid.

\section{Conflicts of Interest}

The authors declare no conflicts of interest regarding the publication of this paper.

\section{References}

[1] Ranaweera, C.K., Kahol, P.K., Ghimire, M., Mishra, S.R. and Gupta, R.K. (2017) Orange-Peel-Derived Carbon: Designing Sustainable and High-Performance Supercapacitor Electrodes. C-Journal of Carbon Research, 2, Article No. 25. https://doi.org/10.3390/c3030025

[2] Lai, H., Wu, Q., Zhao, J., Shang, L., Li, H., Che, R., et al. (2016) Mesostructured $\mathrm{NiO} / \mathrm{Ni}$ Composites for High-Performance Electrochemical Energy Storage. Energy \& Environmental Science, 9, 2053-2060. https://doi.org/10.1039/C6EE00603E

[3] Poonam, Sharma, K., Arora, A. and Tripathi, S.K. (2019) Review of Supercapacitors: Materials and Devices. Journal of Energy Storage, 21, 801-825. https://doi.org/10.1016/j.est.2019.01.010

[4] Satpathy, S., Das, S. and Bhattacharyya, B.K. (2020) How and Where to Use Super-Capacitors Effectively, an Integration of Review of Past and New Characterization Works on Super-Capacitors. Journal of Energy Storage, 27, Article ID: 101044. 
https://doi.org/10.1016/j.est.2019.101044

[5] Jyothibasu, J.P. and Lee, R.-H. (2018) Facile, Scalable, Eco-Friendly Fabrication of High-Performance Flexible All-Solid-State Supercapacitors. Polymers, 10, Article No. 1247. https://doi.org/10.3390/polym10111247

[6] Ho, K.-C. and Lin, L.-Y. (2012) A Review of Electrode Materials Based on Core-Shell Nanostructures for Electrochemical Supercapacitors. Journal of Materials Chemistry $A, 7,3516-3530$. https://doi.org/10.1039/C8TA11599K

[7] Banerjee, S., Sinha, P., Dev Verma, K., Pal, T., De, B., Cherusseri, J., et al. (2020) Capacitor to Supercapacitor. In: Kar, K., Ed., Handbook of Nanocomposites Supercapacitor Materials, Springer, Cham, 53-89.

https://doi.org/10.1007/978-3-030-43009-2_2

[8] Liang, Z., Zhang, L., Liu, H., Zeng, J., Zhou, J., Li, H., et al. (2019) Formation of Monodisperse Carbon Spheres with Tunable Size via Triblock Copolymer-Assisted Synthesis and Their Capacitor Properties. Nanoscale Research Letters, 14, Article No. 124. https://doi.org/10.1186/s11671-019-2952-8

[9] Wang, Y., Song, Y. and Xia, Y. (2016) Electrochemical Capacitors: Mechanism, Materials, Systems, Characterization and Applications. Chemical Society Reviews, 45, 5925-5950. https://doi.org/10.1039/C5CS00580A

[10] Mishra, A.K. and Ramaprabhu, S. (2011) Functionalized Graphene-Based Nanocomposites for Supercapacitor Application. Journal of Physical Chemistry C, 115, 14006-14013. https://doi.org/10.1021/jp201673e

[11] Gopi, C.V.V.M., Ravi, S., Rao, S.S., Reddy, A.E. and Kim, H. (2017) Carbon Nanotube/Metal-Sulfide Composite Flexible Electrodes for High-Performance Quantum Dot-Sensitized Solar Cells and Supercapacitors. Scientific Reports, 7, Article No. 46519. https://doi.org/10.1038/srep46519

[12] Hasan, M., Hossain, E., Mamun, M.A. and Ehsan, M.Q. (2012) Study of Redox Behavior of $\mathrm{Cd}(\mathrm{II})$ and Interaction of $\mathrm{Cd}(\mathrm{II})$ with Proline in the Aqueous Medium Using Cyclic Voltammetry. Journal of Saudi Chemical Society, 16, 145-151. https://doi.org/10.1016/j.jscs.2011.06.006

[13] Du, L., Yang, P., Yu, X., Liu, P., Song, J. and Mai, W. (2014) Flexible Supercapacitors Based on Carbon Nanotube/ $\mathrm{MnO}_{2}$ Nanotube Hybrid Porous Films for Wearable Electronic Devices. Journal of Materials Chemistry A, 2, 17561-17567. https://doi.org/10.1039/C4TA04431B

[14] Sagadevan, S., Chowdhury, Z.Z., Rafie Bin Johan, M., Abdul Aziz, F., Selva Roselin, L., Hsu, H.-L. and Selvin, R. (2019) Synthesis, Characterization and Electrochemical Properties of Cadmium Sulfide-Reduced Graphene Oxide Nanocomposites. Results in Physics, 12, 878-885. https://doi.org/10.1016/j.rinp.2018.12.058

[15] Banerjee, S. and Wong, S.S. (2003) In Situ Quantum Dot Growth on Multiwalled Carbon Nanotubes. Journal of the American Chemical Society, 125, 10342-10350. https://doi.org/10.1021/ja035980c

[16] Zhu, J.-J., Li, J.-J., Huang, H.-P. and Cheng, F.-F. (2013) Quantum Dot-Fluorescence-Based Biosensing. In: Quantum Dots for DNA Biosensing, Springer, Berlin, Heidelberg, 9-25. https://doi.org/10.1007/978-3-642-44910-9_3

[17] Paul, S., Lee, Y., Choi, J., Kang, Y.C. and Kim, D. (2010) Synthesis and Electrochemical Characterization of Polypyrrole/Multi-Walled Carbon Nanotube Composite Electrodes for Supercapacitor Applications. Bulletin of the Korean Chemical Society, 31, 1228-1232. https://doi.org/10.5012/bkcs.2010.31.5.1228

[18] Goswami, M., Ghosh, R., Maruyama, T. and Meikap, A.K. (2016) Polyaniline/Carbon Nanotube/CdS Quantum Dot Composites with Enhanced Optical and 
Electrical Properties. Applied Surface Science, 364, 176-180. https://doi.org/10.1016/j.apsusc.2015.12.101

[19] Zhang, X., Zhang, J., Wang, R. and Zhu, T. (2004) Surfactant-Directed Polypyrrole/CNT Nanocables: Synthesis, Characterization, and Enhanced Electrical Properties. ChemPhysChem, 5, 998-1002. https://doi.org/10.1002/cphc.200301217

[20] Le, T.-H., Kim, Y. and Yoon, H. (2017) Electrical and Electrochemical Properties of Conducting Polymers. Polymers, 9, Article No. 150. https://doi.org/10.3390/polym9040150

[21] Zhang, B., Xu, Y., Zheng, Y., Dai, L., Zhang, M., Yang, J., et al. (2011) A Facile Synthesis of Polypyrrole/Carbon Nanotube Composites with Ultrathin, Uniform and Thickness-Tunable Polypyrrole Shells. Nanoscale Research Letters, 6, Article No. 431. https://doi.org/10.1186/1556-276X-6-431

[22] Inoue, F., Ando, R.A., Izumi, C.M.S. and Corio, P. (2014) Spectroscopic Characterization of Carbon Nanotube-Polypyrrole Composites. Journal of Physical Chemistry $C, 118,18240-18248$. https://doi.org/10.1021/jp505525k

[23] Madani, A., Nessark, B., Boukherroub, R. and Chehimi, M.M. (2011) Preparation and Electrochemical Behaviour of PPy-CdS Composite Films. Journal of Electroanalytical Chemistry, 650, 176-181. https://doi.org/10.1016/j.jelechem.2010.10.017

[24] Lee, S.W., Kim, B., Chen, S., Shao-Horn, Y. and Hammond, P.T. (2009) Layer-by-Layer Assembly of All Carbon Nanotube Ultrathin Films for Electrochemical Applications. Journal of the American Chemical Society, 131, 671-679. https://doi.org/10.1021/ja807059k

[25] Zhi, M., Xiang, C., Li, J., Li, M. and Wu, N. (2013) Nanostructured Carbon-Metal Oxide Composite Electrodes for Supercapacitors: A Review. Nanoscale, 5, 72-88. https://doi.org/10.1039/C2NR32040A

[26] Khan, Y., Siddiqui, A. and Ahmad, A. (2019) Devising Carbon Nanotube, Green Tea, and Polyaniline Based Nanocomposite plus Investigating Its Rheological together with Bactericidal Efficacies. ACS Omega, 4, 16956-16962. https://doi.org/10.1021/acsomega.9b02317

[27] Gottimukkala, K.S.V., Harika Reddy, P. and Deeveka, Z. (2017) Green Synthesis of Iron Nanoparticles Using Green Tea leaves Extract. Journal of Nanomedicine and Biotherapeutic Discovery, 7, Article No. 151. https://doi.org/10.4172/2155-983X.1000151

[28] Cai, Z. and Yan, X. (2006) In Situ Electrostatic Assembly of CdS Nanoparticles onto Aligned Multiwalled Carbon Nanotubes in Aqueous Solution. Nanotechnology, 17, Article No. 4212. https://doi.org/10.1088/0957-4484/17/16/035

[29] Ramesh, S., Haldorai, Y., Kim, H.S. and Kim, J.-H. (2017) A Nanocrystalline $\mathrm{Co}_{3} \mathrm{O}_{4} @$ Polypyrrole/MWCNT Hybrid Nanocomposite for High Performance Electrochemical Supercapacitors. RSC Advances, 7, 36833-36843.

https://doi.org/10.1039/C7RA06093A

[30] Dai, K., Peng, T., Ke, D. and Wei, B. (2009) Photocatalytic Hydrogen Generation Using a Nanocomposite of Multi-Walled Carbon Nanotubes and $\mathrm{TiO}_{2}$ Nanoparticles Under Visible Light Irradiation. Nanotechnology, 20, Article ID: 125603. https://doi.org/10.1088/0957-4484/20/12/125603

[31] Ma, L.L., Sun, H.Z., Zhang, Y.G., Lin, Y.L., Li, J.-L., Wang, E.-K., et al. (2008) Preparation, Characterization and Photocatalytic Properties of CdS Nanoparticles Dotted on the Surface of Carbon Nanotubes. Nanotechnology, 19, Article ID: 115709. https://doi.org/10.1088/0957-4484/19/11/115709

[32] Du, Y., Xu, J. and Lin, T. (2018) Single-Walled Carbon Nanotube/Polypyrrole 
Thermoelectric Composite Materials. IOP Conference Series. Earth and Environmental Science, 108, Article ID: 022040. https://doi.org/10.1088/1755-1315/108/2/022040

[33] Zhang, D., Dong, Q., Wang, X., Yan, W., Deng, W. and Shi, L. (2013) Preparation of a Three-Dimensional Ordered Macroporous Carbon Nanotube/Polypyrrole Composite for Supercapacitors and Diffusion Modeling. Journal of Physical Chemistry C, 117, 20446-20455. https://doi.org/10.1021/jp405850w

[34] Robel, B.I., Bunker, B.A. and Kamat, P.V. (2005) Single-Walled Carbon Nanotube-CdS Nanocomposites as Light-Harvesting Assemblies: Photoinduced ChargeTransfer Interactions. Advanced Materials, 17, 2458-2463.

https://doi.org/10.1002/adma.200500418

[35] Cao, B.J., Sun, J., Hong, J., Li, H., Chen, H. and Wang, M. (2004) Carbon Nanotube/CdS Core-Shell Nanowires Prepared by a Simple Room-Temperature Chemical Reduction Method. ChemInform, 35, 2002-2005. https://doi.org/10.1002/chin.200413206

[36] Vinoth Kumar, V.M.J., Karthik, R., Chen, S.-M., Raja, N., Selvam, V. and Muthuraj, V. (2017) Evaluation of a New Electrochemical Sensor for Selective Detection of Non-Enzymatic Hydrogen Peroxide Based on Hierarchical Nanostructures of Zirconium Molybdate. Journal of Colloid and Interface Science, 500, 44-53. https://doi.org/10.1016/j.jcis.2017.03.113

[37] Jyothibasu, J.P. and Lee, R. (2018) Facile, Scalable, Eco-Friendly Fabrication of High-Performance Flexible All-Solid-State Supercapacitors. Polymers MDPI, 10, 1-8. https://doi.org/10.3390/polym10111247

[38] Deshmukh, M.A., Bodkhe, G.A., Shirsat, S., Ramanavicius, A. and Shirsat, M.D. (2018) Nanocomposite Platform Based on EDTA Modified Ppy/SWNTs for the Sensing of $\mathrm{Pb}$ (II) Ions by Electrochemical Method. Frontiers in Chemistry, 6, Article No. 451. https://doi.org/10.3389/fchem.2018.00451

[39] Purty, B., Choudhary, R.B., Biswas, A. and Udayabhanu, G. (2018) Potentially Enlarged Supercapacitive Values for CdS-PPY Decorated rGO Nanocomposites as Electrode Materials Potentially Enlarged Supercapacitive Values for CdS-PPY Decorated rGO Nanocomposites as Electrode Materials. Materials Chemistry and Physics, 216, 213-222. https://doi.org/10.1016/j.matchemphys.2018.06.015

[40] Kurniawan, F., Al Kiswiyah, N.S., Madurani, K.A. and Tominaga, M. (2018) Electrochemical Sensor Based on Single-Walled Carbon Nanotubes-Modified Gold Electrode for Uric Acid Detection. Journal of The Electrochemical Society, 165, 515-522. https://doi.org/10.1149/2.0991811jes

[41] Bushra, R., Shahadat, M., Khan, M.A., Inamuddin, Adnan, R. and Rafatullah, M. (2014) Optimization of Polyaniline Supported Ti(IV) Arsenophosphate Composite Cation Exchanger Based Ion-Selective Membrane Electrode for the Determination of Lead. Industrial \& Engineering Chemistry Research, 53, 19387-19391. https://doi.org/10.1021/ie5034655

[42] Liu, Y., She, P., Gong, J., Wu, W., Xu, S., Li, J., et al. (2015) A Novel Sensor Based on Electrodeposited Au-Pt Bimetallic Nano-Clusters Decorated on Graphene Oxide (GO)-Electrochemically Reduced GO for Sensitive Detection of Dopamine and Uric Acid. Sensors and Actuators B: Chemical, 221, 1542-1553.

https://doi.org/10.1016/j.snb.2015.07.086

[43] Cheng, Q., Tang, J., Ma, J., Zhang, H., Shinya, N. Qin, L.-C. (2011) Graphene and Carbon Nanotube Composite Electrodes for Supercapacitors with Ultra-High Energy Density. Physical Chemistry Chemical Physics, 13, 17615-17624.

https://doi.org/10.1039/c1cp21910c 
[44] Bushra, R., Arfin, T., Oves, M., Raza, W., Faruq, M., Khan, M.A., et al. (2016) Development of PANI/MWCNTs Decorated with Cobalt Oxide Nanoparticles towards Multiple Electrochemical. Photocatalytic and Biomedical Application Sites. New Journal of Chemistry, 40, 9448-9459. https://doi.org/10.1039/C6NJ02054B

[45] Xu, R., Guo, F., Cui, X., Zhang, L., Wang, K. and Wei, J. (2015) High Performance Carbon Nanotube Based Fiber-Shaped Supercapacitors Using Redox Additives of Polypyrrole and Hydroquinone. Journal of Materials Chemistry A, 3, 22353-22360. https://doi.org/10.1039/C5TA06165B

[46] Ahmad, T., Phula, R., Khatoon, N. and Sardar, M. (2017) Antibacterial Efficacy of Ocimum Sanctum Leaf Extract Treated Iron Oxide Nanoparticles. New Journal of Chemistry, 41, 2055-2061. https://doi.org/10.1039/C7NJ00103G

[47] Ahmad, R., Mohsin, M., Ahmad, T. and Sardar, M. (2014) Alpha Amylase Assisted Synthesis of $\mathrm{TiO}_{2}$ Nanoparticles: Structural Characterization and Application as Antibacterial Agents. Journal of Hazardous Materials, 283, 171-177.

https://doi.org/10.1016/j.jhazmat.2014.08.073 